\title{
Illness-related behaviour and utilization of oral health services among adult city-dwellers in Burkina Faso: evidence from a household survey
}

\author{
Benoît Varenne*1, Poul Erik Petersen ${ }^{2}$, Florence Fournet ${ }^{1}$, Philippe Msellati ${ }^{3}$, \\ Jean Gary ${ }^{1}$, Seydou Ouattara ${ }^{4}$, Maud Harang ${ }^{1}$ and Gérard Salem ${ }^{1,5}$
}

\begin{abstract}
Address: ${ }^{1}$ UR178, Institut de Recherche pour le Développement, 01 BP 182 Ouagadougou 01, Burkina Faso, ${ }^{2}$ World Health Organization Globa Oral Health Programme, Department of Chronic Disease and Health Promotion, World Health Organization, 20, Avenue Appia, CH-1211 Geneva 27, Switzerland, ${ }^{3}$ UMR145, Institut de Recherche pour le Développement, 01 BP 171 Bobo Dioulasso 01, Burkina Faso, ${ }^{4}$ Centre Muraz, Ministry of Health of Burkina Faso, 01 BP 390 Bobo-Dioulasso 01, Burkina Faso and ${ }^{5}$ Université Paris X Nanterre, Laboratoire Espace, Santé et Territoire, 200 Avenue de la République, 92001 Nanterre Cedex, France

Email: Benoît Varenne* - benoit.varenne@ird.bf; Poul Erik Petersen - petersenpe@who.ch; Florence Fournet - florence.fournet@ird.bf; Philippe Msellati - philippe.msellati@ird.bf; Jean Gary - jeangary2003@yahoo.fr; Seydou Ouattara - seyduouatt@yahoo.fr;

Maud Harang - maud.harang@ird.bf; Gérard Salem - gsalem@ext.jussieu.fr

* Corresponding author
\end{abstract}

Published: 27 December 2006

BMC Health Services Research 2006, 6:164 doi:10.1 186/1472-6963-6-164

This article is available from: http://www.biomedcentral.com//472-6963/6/164

(c) 2006 Varenne et al; licensee BioMed Central Ltd.

This is an Open Access article distributed under the terms of the Creative Commons Attribution License (http://creativecommons.org/licenses/by/2.0), which permits unrestricted use, distribution, and reproduction in any medium, provided the original work is properly cited.

\begin{abstract}
Background: In sub-Saharan Africa, the availability and accessibility of oral health services are seriously constrained and the provision of essential oral care is limited. Reports from the region show a very low utilization of oral health care services, and visits to dental-care facilities are mostly undertaken for symptomatic reasons. The objectives of the present study were to describe the prevalence of oral symptoms among adults in Ouagadougou, capital city of Burkina Faso and the use of oral health services and self-medication in response to these symptoms and to measure the associations between predisposing, enabling and needs factors and decisions to seek oral health care.
\end{abstract}

Methods: The conceptual design of the study was derived from both the Andersen-Newman model of health care utilization and the conceptual framework of the WHO International Collaborative Study of Oral Health Outcomes. Data were obtained by two-stage stratified sampling through four areas representative of different stages of urbanization of Ouagadougou. The final study population comprised 3030 adults aged I5 years or over and the response rate was $65 \%$.

Results: Overall, $28 \%$ of the respondents had experienced an oral health problem during the past 12 months; a high proportion (62\%) reported pain or acute discomfort affecting daily life. In response to symptoms, only $28 \%$ used oral health facilities, $48 \%$ used self-medication and $24 \%$ sought no treatment at all. Multivariate analyses revealed that several socio-economic and socio-cultural factors such as religious affiliation, material living conditions and participation in a social network were significantly associated with the use of oral health care services by adults who had experienced oral health problems during the previous year.

Conclusion: The proportion of people who have obtained oral health care is alarmingly low in Ouagadougou and self-medication appears to be an important alternative source of care for adult city-dwellers. Decision-makers in sub-Saharan countries must seek to ensure that access to essential oral health care is improved. 


\section{Background}

In sub-Saharan Africa, communicable diseases are still major threats to health but the burden of chronic diseases and injuries are expected to increase rapidly [1]. The epidemiological transition in relation to oral health is particularly apparent in the growing incidence of dental diseases such as caries and periodontal conditions. Other conditions such as oral cancer, oral manifestations of HIV/AIDS and dental trauma are also expected to increase in the near future [2].

In many African countries, the availability and accessibility of oral health services are seriously constrained, and the provision of essential oral care is limited. Many studies have been undertaken in industrialised countries to assess the level and the pattern of utilization of dental health services $[3,4]$. Unfortunately, this has been a neglected field of research in Africa. The few existing reports from the region show very low utilization of oral health care services, and visits to a dental-care facility are mostly undertaken for symptomatic reasons [5-8]. A survey conducted in a peri-urban settlement of South Africa found that $37.0 \%$ of adults had consulted a dentist or medical practitioner, usually for tooth extractions [6]. A study in the Ivory Cost reported that only $11.4 \%$ of the city-dwellers in Abidjan had visited a dentist because of dental problems [7]. Another study in Nigeria showed that $9.0 \%$ of households had used dental services during the past year while variables such as "zone of residence" and "household educational and social class ranking" affected use of oral care services [8]. In Tanzania, the principal factors associated with the utilization of oral health care services were distance to treatment facility and previous dental symptoms [9]. Concomitantly, self-medication with herbal medicines or modern drugs seems to be a common practice in many African countries [10,11].

Systematic studies of the utilization of oral health services and the factors involved in seeking health care are urgently needed so that oral health programmes may be developed to match the needs of the population. The objectives of the present study were to describe the prevalence of oral symptoms among urban adults and the use of oral health services and self-medication in response to these symptoms, and to analyze the associations between predisposing, enabling and needs factors and decisions about seeking oral health care. This study is part of a larger research programme carried out by the Institut de Recherche pour le Développement (IRD) to assess social and spatial health disparities in Ouagadougou.

\section{Methods \\ Study area}

Ouagadougou, the capital city of Burkina Faso, is experiencing an urban population boom, with expected increases in poverty and health disparities typical of many other major towns in sub-Saharan Africa $[12,13]$. Between the years 1980 and 2005, the population of Ouagadougou grew more than four-fold, from 280,000 to $1,200,000$ inhabitants. More than $25.0 \%$ of the population currently live in irregular peri-urban settlements of the town characterized by poorly constructed houses, poor sanitary conditions and lack of all services.

Like the general health services, oral health care in Burkina Faso has been organized through a public/private mixture of providers based on an out-of-pocket payment system. The national health insurance system does not cover any costs of curative dental care. The dentist to population ratio for the whole country is one per 220,000. Oral health facilities in the capital city are somewhat better equipped and definitely more numerous than in other parts of the country. In 2005, 24 oral health care services were established in Ouagadougou: 14 facilities within the private health sector, 4 within the public health sector and 6 within the nongovernmental not-for-profit health sector [14]. In parallel, a large number of pharmacies, streetmarket traders and traditional healers play a significant role in providing oral health care.

\section{Study design and sample}

To tackle the complex health problems resulting from environmental and social changes in an urban setting, the whole research approach has to be multi-disciplinary in accordance with epidemiological and geographical constraints.

Because of heterogeneity of ecological situations within the capital city and the absence of recent socio-demographic census data, a two-stage stratified sampling technique was used. The purpose was to identify various ecological settings representative of the distinct levels of urbanization in Ouagadougou. The stratification process was based on two criteria: building density, by comparing "average building density" with "high building density"; and settlement subdivision, by comparing "regular settlements" with "irregular settlements". Building density, the first criterion of stratification, was evaluated using a SPOT 5 (Satellite Pour l'Observation de la Terre) panchromatic satellite image of Ouagadougou dated November 26, 2002. In brief, ERDAS Imagine ${ }^{\odot}$ software was used to locate buildings, and Arc GIS $8.2^{\circ}$ made it possible to calculate the density of the built-up area. The process was supplemented and validated by field investigation. The localization of settlement subdivisions, the second criterion of stratification, was established using administrative information, the SPOT 5 image and field observations. The regular settlements are characterized by a network of hierarchical streets and the presence of basic services and infrastructures as electricity and water. In contrast, the 
irregular settlements are defined by an important but disorganized network of tracks and the absence of services and infrastructures. At the conclusion of this exercise, urban stratification comprised four types of urban situations: "regular settlements with average building density", "regular settlements with high building density", "irregular settlements with average building density" and "irregular settlements with high building density" [15].

In each of the four principal areas identified, two subareas were chosen by convenience sampling as representative of their geographical location in the city (central or peripheral) and age of housing construction (old or recent). At the second level of sampling, a random selection of households was chosen. In regular sub-areas, yards were randomly selected through cadastral maps. In irregular sub-areas, random sampling could not be applied because there was no cadastral map, so households were selected by the "door-to-door" approach used in the standard Expanded Program of Immunisation (EPI) sampling method [16]. In brief, from each randomly selected starting point, the closest household was chosen and checked for compliance with the inclusion criteria. From this first household, the interviewers moved to the next household according to well-defined rules [16] until four households had been randomly chosen. The same process was repeated from other starting points until the required number of participants was obtained.

As the whole research program focused on the impacts of urban life on disparities in health, an "urban criterion", the duration of residence in Ouagadougou of the head of the household, was taken into consideration. In each randomly selected yard, households were eligible if the head of the household had been born in Ouagadougou or had lived in Ouagadougou for more than five years. In addition, the householder had to be over 34 years old to comply with the WHO standard monitoring group for health conditions among adults. In each qualified household, eligible participants were women of any age and men of 35 years or older. All participants were required to have kinship or marital relationships with the head of the household.

\section{Data collection}

Data were collected by face-to-face field interviews, based on structured questionnaires, conducted either in households or in temporary medical examination centres. Interviewers fluent in the local language were given an intensive three-day field-training program. The survey instrument was evaluated for face validity and pilot tested before use.

\section{Conceptual framework}

In 1973, Andersen and Newman [17] proposed a framework for evaluating the utilization of health care. This model assumes that a person's use of health services is a function of predisposing, enabling and need factors. Predisposing characteristics include gender, marital status, educational level, occupation, length of time in the community and health beliefs. Health beliefs - such as attitudes, values and knowledge of the dental care delivery system - are often influenced by cultural values. Enabling resources refer to attributes specific to the individual or the community (e.g. income, social network, access to regular source of care). Need variables reflect illness levels that require the use of services. Needs can be perceived by the individual and are influenced by cultural beliefs and values (e.g. perceived health status, disease severity, limitation of activity) [18]. In 1997, an expanded version of this model was developed as a conceptual framework for the WHO International Collaborative Study of Oral Health Outcomes (ICS II), which was undertaken in selected industrialized countries [4]. This theoretical model was derived by integrating existing oral health behaviour and oral health status models with the general health model of Andersen and Newman. In the present study, we adapted the individual-level determinants proposed in both models to an urban setting of Burkina Faso.

We defined a set of independent individual-level variables that may influence utilization of oral health care: (1) predisposing socio-demographic and health beliefs factors, which can be either modifiable (e.g. education, marital status or health attitudes such as perceived general health status and seriousness of oral disease, importance of oral health, benefits of brushing, or perceived barriers to obtaining oral health care) or non-modifiable (e.g. age or sex); (2) enabling characteristics, which refer to specific attributes of the individual or the community in which the individual lives (e.g. level of income, residence, family size, integration in urban life, social support) and may affect ability to access the health care system; and (3) need factors, which reflect the perceived need for oral health care (patient's perceptions of illness, impairment of quality of life) or the self assessment of health status.

Furthermore, because of the complexity of assessing the socio-economic level of households, a composite index for material living conditions of households was computed using the SPSS 13.0. Module of Multiple Correspondence Analysis. This index was based on ownership of certain household assets such as refrigerator, television, motorcycle and car. Finally, the dependent variables were: whether individuals had experienced an oral health problem during the past twelve months; whether they practised self-medication; and whether they made a dental 
visit. No distinction was made between preventive and curative visits.

\section{Statistical analysis}

The data were processed and analyzed by SPSS 13.0. First, characteristics of the study sample were described, then frequency distributions were used to highlight the sociodemographic status of participants who had or not experienced an oral problem within the past twelve months. Secondly, chi-square tests were used to detect statistically significant proportions of people who used oral health facilities only, people who practised self-medication only, and people who did not seek treatment at all, in relation to various independent variables. Thirdly, logistic regression was performed in order to estimate the relative risk (Odds Ratio) of the independent variables explaining the use of oral health services within one year. The full regression model was specified on the basis of the theoretical model (the Anderson and Newman model). Our general approach was to test the predisposing characteristics first, then the enabling variables, and then the need variables. Estimates are presented with $95 \%$ confidence intervals. Results were weighted using the sampling proportions in order to reflect the population in the strata studied. There were no major differences in estimates when the sample data rather than weighted data were used. In addition, a multi-colinearity diagnostic statistic was derived from the Variance Inflation Factor for each variable found to be significantly associated with our dependent variable.

\section{Results}

\section{Sampling characteristics}

The overall rate of participation of people in the study was $65.0 \%$. The final sample consisted of 3030 adult citydwellers aged 15 years or over and living in 1816 households of Ouagadougou. For variables such as age, gender, religion, ethnic group and number of years spent in Ouagadougou, we compared non-respondents and respondents. No differences in participation rate were found among socio-demographic groups, except for the relationship with gender. The participation rate was lower among men than women because men left the house early in the morning to go to work and came back late in the evening. Twenty-seven percent of the respondents were born in Ouagadougou and $44.0 \%$ had been resident in the city for 5-20 years. About two-thirds (67.4\%) of the sample were women.

\section{Experience of oral health problems}

Overall, 27.7\% indicated that they had experienced an oral problem within the past 12 months. Women in general, and first spouses of the head of household in particular, seemed to be most affected $(\mathrm{p}<0.05)$ by oral problems (Table 1). Among those declaring oral problems, a high proportion (62.1\%) reported the experience of toothache caused by hot, cold or sweet food items while $43.6 \%$ of adults indicated pain when they chewed hard items. In addition, $27.3 \%$ of respondents stated that they had trouble sleeping because of pain and $21.0 \%$ of adults reported having fever and an abscess in the mouth.

\section{Decision-making in seeking oral health care}

Among individuals who reported having experienced an oral health problem, only $27.7 \%$ used oral health facilities, $47.7 \%$ reported self-medication and $24.1 \%$ chose no treatment at all (Figure 1). In addition, $54.5 \%$ of the adults who used oral health facilities claimed that oral problems limited their usual activities, against $38.3 \%$ and $24.1 \%$, respectively, of those who used self-medication or no treatment at all. Among adults who consulted medical providers, $64.3 \%$ visited public or nongovernmental dental services but $24.1 \%$ of them attended a primary health

Table I: Socio-demographic characteristics of adults having experienced an oral health problem

\begin{tabular}{|c|c|c|}
\hline Independent variables & $\mathrm{n}$ & $\%$ \\
\hline \multicolumn{3}{|l|}{ Age group, years $(n=3025)$} \\
\hline 15 to 24 & 267 & 20.2 \\
\hline 25 to 34 & 689 & 27.4 \\
\hline 35 to 44 & $103 \mid$ & 27.4 \\
\hline 45 to 54 & 523 & 27.0 \\
\hline Over 54 & 515 & 27.2 \\
\hline \multicolumn{3}{|l|}{ Gender $(n=3030)$} \\
\hline Female & 2042 & $27.8^{a}$ \\
\hline Male & 988 & 24.4 \\
\hline \multicolumn{3}{|l|}{ Household marital status $(n=3029)$} \\
\hline Household chief & 1088 & 25.4 \\
\hline First spouse of household chief & 1056 & $29.9 \mathrm{~b}$ \\
\hline Others members of household & 885 & 24.5 \\
\hline \multicolumn{3}{|l|}{ Level of education obtained $(n=3015)$} \\
\hline High & 564 & 24.5 \\
\hline Low & 806 & 27.4 \\
\hline None & 1645 & 27.1 \\
\hline \multicolumn{3}{|l|}{ Occupational status $(\mathrm{n}=3019)$} \\
\hline Employee & 473 & 24.7 \\
\hline Housewife & 743 & 26.0 \\
\hline Independent workers & 1060 & 28.9 \\
\hline Without occupation & 380 & 26.3 \\
\hline Others & 363 & 25.3 \\
\hline \multicolumn{3}{|l|}{ Religion $(n=2982)$} \\
\hline Christian/Animist & 1283 & 26.9 \\
\hline Muslim & 1699 & 26.8 \\
\hline \multicolumn{3}{|c|}{ Material living conditions of household $(n=3030)$} \\
\hline Low & $|82|$ & 28.1 \\
\hline Medium & 654 & 24.8 \\
\hline High & 555 & 24.5 \\
\hline \multicolumn{3}{|l|}{ Urban life experience $(n=2948)$} \\
\hline Short (from 5 to 10 years) & 582 & 27.0 \\
\hline Medium (from II to 20 years) & 718 & 29.4 \\
\hline Long (more than 21 years) & 1648 & 25.1 \\
\hline
\end{tabular}

${ }^{a} p<0.05{ }^{b} p<0.01$ 


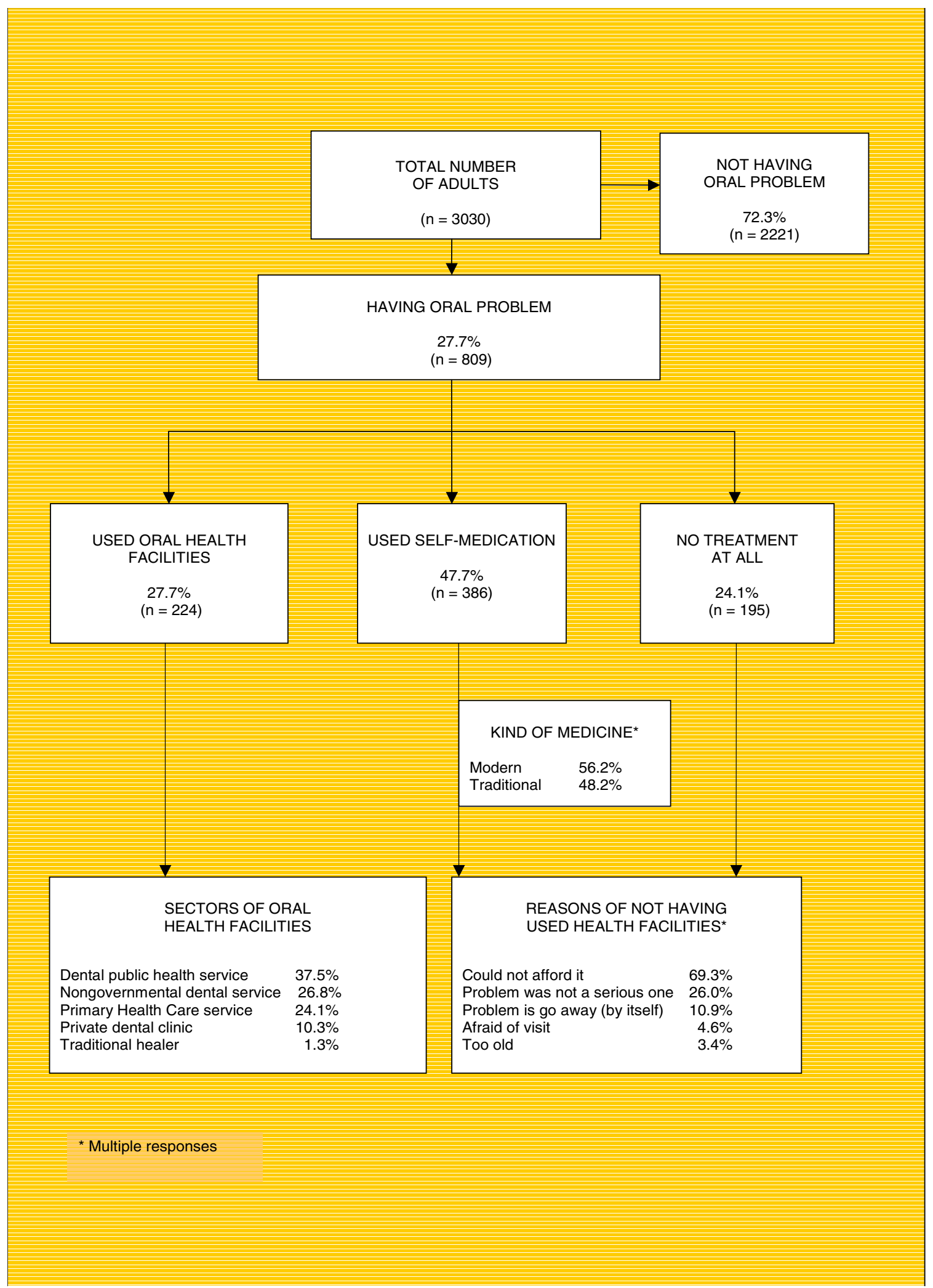

Figure I

Responses to oral symptoms. 
care service with no dental staff. Only 1.3\% declared that they had seen a traditional healer. Of the respondents with oral health problems who did not visit an oral health care facility, $69.3 \%$ emphasized that it was because of the high cost. Those who relied on self-medication were more likely to report use of modern medicines (56.2\%) than traditional ones $(48.2 \%)$.

\section{Predisposing characteristics}

Table 2 shows the results of bivariate analysis of oral health care choices among adults who reported that they had experienced an oral problem during the previous 12 months in relation to selected predisposing variables. High school graduates, employees, and persons with relatively high material living conditions and residing in a house constructed of modern materials were more likely to visit services for oral health care. No statistically significant differences in illness-related behaviour were found by sex or age. The results also suggest that adults were more likely to use oral health facilities if they perceived oral disease to be important as other health problems or considered fluoride prevents tooth decay and dental visits to have important benefits. Persons who believed that going to the dentist is synonymous with pain were also the most likely to visit oral health providers.

\section{Enabling and need characteristics}

Table 3 outlines the choices of oral health care among adults who reported that they had experienced an oral problem during the previous 12 months in relation to selected enabling and perceived needs variables. Overall, residents of regular areas with high building density and adults with long urban life experience were more likely to use oral health facilities. In addition, participants with active social networks were most likely to have made a visit. Respondents who were very satisfied with the appearance of their teeth and persons who declared that oral problems limited their usual activities were more likely to visit oral health care providers.

\section{Multivariate analysis}

The results of logistic regression analysis of the predictors for using oral health care facilities are summarised in Table 4. Various predisposing factors significantly increased the probability of using oral health care facilities, including Christian affiliation and moderate or high material living conditions. Adults in the "25-34" age group were likely to use oral health facilities. The two indicators of health beliefs were significantly associated with use of oral health services. First, adults who perceived oral disease to be just as important as general diseases were most likely to have made a visit. Second, those who disagreed with the statement that going to the dentist always entails pain were less likely to use oral health facilities. In addition, persons with active social networks and individuals with motorised transport had a higher probability of using oral health care facilities. All other factors being equal, people with the highest perception of impairment in the event of oral problems had a very high probability of having made a visit.

\section{Discussion}

Our data on urban people in Burkina Faso show that oral self-care is practised in accordance with both traditional and modern self-medication cultures. Impairment of function and poor quality of life are also observed in high proportions of individuals who claimed to have their usual activities restricted by oral problems. Moreover, we have identified socio-economic and socio-cultural factors as potentials barriers to the use of oral health facilities. Relatively little is known about oral health service utilization patterns among populations of African countries. The intention of the study was to analyse responses to illness episodes and oral health seeking behaviour among adult city-dwellers in a sub-Saharan country (Ouagadougou, Burkina Faso). In particular, an aim of this investigation was to evaluate the association between utilization of oral health facilities and certain predisposing, enabling and need barriers and facilitators.

In developing countries, random sampling is largely impossible because of the lack of census lists or valid population registers, so alternative procedures are needed to obtain representative samples. In irregular sub-areas, few sampling methods are available for surveying households. In the present study, we applied the "door-to-door" method used in the standard Expanded Program of Immunisation (EPI) developed by WHO [16]. Although this method suffers from a number of disadvantages and was initially developed to measure the coverage of the childhood immunization programmes and nutritional status, it has been widely and successfully used for other purposes in low income countries $[19,20]$. Furthermore, the response rate is acceptable and only minor differences in socio-demographic profiles among participants and non-participants were noted. Despite the limitations, for those members of the study population who met the eligibility criteria for the study, the data allow reasonable inferences to be drawn about the factors most significantly associated with the use of dental services in the study area.

Studies examining the utilization of oral health care service have measured dependent variables in different ways [3]. The percentage of persons reporting or not reporting a visit to a dentist within the past year is one commonly used parameter for assessing the utilization of dental services. In the context of developing countries where dental visiting habits are primarily orientated towards relief of symptoms or pain rather than preventive care, it seems particularly relevant to express data concerning utilization 
Table 2: Percentages of adults who reported experiencing an oral problem during the past 12 months by choice of oral health care in relation to selected predisposing factors

\begin{tabular}{|c|c|c|c|c|}
\hline Independent variables & $\mathrm{n}$ & $\begin{array}{l}\text { Used health facilities } \\
\%\end{array}$ & $\begin{array}{c}\text { Used self-medication } \\
\%\end{array}$ & $\begin{array}{c}\text { No treatment at all } \\
\%\end{array}$ \\
\hline \multicolumn{5}{|l|}{ Level of education obtained } \\
\hline High & 138 & $41.6 \mathrm{c}$ & 35.7 & 22.7 \\
\hline Low & 221 & 32.0 & 49.2 & 18.8 \\
\hline None & 445 & 21.8 & $50.9 \mathrm{~b}$ & $27.3^{\mathrm{a}}$ \\
\hline \multicolumn{5}{|l|}{ Occupational status } \\
\hline Employee & 117 & $38.5^{b}$ & 37.6 & 23.9 \\
\hline Housewife & 193 & 19.7 & 53.4 & 26.9 \\
\hline Independent workers & 306 & 27.5 & 48.1 & 23.5 \\
\hline Without occupation & 100 & 27.0 & 48.0 & 25.0 \\
\hline Others & 92 & 33.6 & 46.8 & 19.6 \\
\hline \multicolumn{5}{|l|}{ Religion } \\
\hline Christian/Animist & 345 & $34.5^{c}$ & 40.9 & 24.6 \\
\hline Muslim & 456 & 23.6 & $52.7^{b}$ & 23.7 \\
\hline \multicolumn{5}{|l|}{ Material living conditions of household } \\
\hline Low & 511 & 19.3 & $53.4^{c}$ & $27.3^{\mathrm{a}}$ \\
\hline Medium & 162 & 35.8 & 44.4 & 19.8 \\
\hline High & 136 & $50.5^{c}$ & 31.4 & I8.1 \\
\hline \multicolumn{5}{|l|}{ Type of house } \\
\hline Modern building materials & 219 & $40.6^{c}$ & 36.5 & 21.5 \\
\hline Mixed building materials & 434 & 24.2 & 50.0 & 25.8 \\
\hline Traditional building materials (mud) & 154 & 19.5 & $56.5^{c}$ & 23.4 \\
\hline \multicolumn{5}{|c|}{ Oral diseases are as important as other health problems } \\
\hline Agree & 671 & $30.4^{b}$ & 47.7 & 21.9 \\
\hline Disagree & 89 & 14.6 & 46.1 & $39.3^{b}$ \\
\hline Do not know & 46 & 17.4 & 56.5 & 26.1 \\
\hline \multicolumn{5}{|l|}{ Oral problems cause other general diseases } \\
\hline Agree & 520 & 29.4 & 50.6 & 20.0 \\
\hline Disagree & 68 & 22.1 & 41.2 & $36.7 c$ \\
\hline Do not know & 207 & 24.7 & 44.4 & 30.9 \\
\hline \multicolumn{5}{|l|}{ Fluoride prevents tooth decay } \\
\hline Agree & 258 & $37.6 \mathrm{c}$ & 40.3 & 20.9 \\
\hline Disagree & 14 & 35.7 & 50.0 & 14.3 \\
\hline Do not know & 533 & 22.9 & $51.0^{\mathrm{a}}$ & 25.9 \\
\hline \multicolumn{5}{|l|}{ Dental visits to have important benefits } \\
\hline Agree & 596 & $31.9 c$ & 46.3 & 21.8 \\
\hline Disagree & 49 & 23.4 & 53.2 & 23.4 \\
\hline Do not know & 162 & 14.2 & 52.5 & $33.3^{\mathrm{b}}$ \\
\hline \multicolumn{5}{|l|}{ Going to dentist is synonymous with pain } \\
\hline Agree & 353 & $36.9 c$ & 41.9 & 21.2 \\
\hline Disagree & 229 & 33.3 & 45.8 & 20.9 \\
\hline Do not know & 225 & 8.5 & $59.3^{c}$ & $32.2^{b}$ \\
\hline
\end{tabular}

${ }^{\mathrm{a}} \mathrm{p}<0.05{ }^{\mathrm{b}} \mathrm{P}<0.01{ }^{\mathrm{c}} \mathrm{p}<0.001$ 
Table 3: Percentages of adults who reported experiencing an oral problem during the past 12 months by choice of oral health care in relation to selected enabling and needs factors

\begin{tabular}{|c|c|c|c|c|}
\hline Independent variables & $\mathrm{n}$ & $\begin{array}{l}\text { Used health facilities } \\
\qquad \%\end{array}$ & $\begin{array}{l}\text { Used self-medication } \\
\%\end{array}$ & $\begin{array}{c}\text { No treatment at all } \\
\%\end{array}$ \\
\hline \multicolumn{5}{|l|}{ Urban life experience } \\
\hline Short (spent from 5 to 10 years) & 157 & 20.6 & 55.0 & 24.4 \\
\hline Medium (spent from II to 20 years) & 211 & 25.6 & 46.9 & 27.5 \\
\hline Long (spent more than 21 years) & 414 & $31.4^{\mathrm{a}}$ & 45.5 & 23.1 \\
\hline \multicolumn{5}{|l|}{ Residence settlement } \\
\hline Irregular settlement with HBD* & 223 & 18.8 & 52.5 & $28.7^{a}$ \\
\hline Irregular settlement with $A B D * *$ & 232 & 26.7 & 50.0 & 23.3 \\
\hline Regular settlement with HBD* & 159 & $42.6^{c}$ & 41.3 & 16.1 \\
\hline Regular settlement with $\mathrm{ABD}$ ** & 195 & 27.5 & 45.6 & 26.9 \\
\hline \multicolumn{5}{|l|}{ Social network } \\
\hline No participation & 534 & 26.2 & 48.3 & 25.5 \\
\hline Weak participation & 161 & 24.8 & 47.9 & $27.3^{\mathrm{a}}$ \\
\hline Active participation & 108 & $41.7 \mathrm{~b}$ & 43.5 & 14.8 \\
\hline \multicolumn{5}{|l|}{ Means of transport in town } \\
\hline Moped or vehicle (car, taxi or bus) & 248 & $49.4^{c}$ & 29.8 & 20.8 \\
\hline On foot or bicycle & 563 & 22.8 & $53.7 \mathrm{c}$ & 23.5 \\
\hline \multicolumn{5}{|l|}{ Satisfaction with appearance of teeth } \\
\hline Yes, very satisfied & 51 & $39.2^{\mathrm{a}}$ & 49.0 & 11.8 \\
\hline Yes, fair & 229 & 32.4 & 39.9 & 27.7 \\
\hline No, dissatisfied & 398 & 24.8 & $51.9 \mathrm{a}$ & 23.3 \\
\hline No, very dissatisfied & 129 & 25.1 & 49.2 & 25.7 \\
\hline \multicolumn{5}{|l|}{ Do you have any natural teeth at all? } \\
\hline Yes & 359 & 24.1 & 46.6 & $29.3^{\mathrm{b}}$ \\
\hline No & 445 & 30.9 & 48.8 & 20.3 \\
\hline \multicolumn{5}{|c|}{ Oral problem caused limitation of usual activities } \\
\hline Yes & 311 & $39.6^{c}$ & 47.8 & 12.6 \\
\hline No & 498 & 20.5 & 47.9 & $31.6^{c}$ \\
\hline
\end{tabular}

${ }^{a} p<0.05$ b $p<0.01{ }^{c} p<0.001$

* High Building Density

** Average Building Density

by people who have experienced oral trouble within the past year.

Compared with western industrialized countries, where about $40-80 \%$ of the adults would have visited a dentist within one year $[3,4,21]$, the use of professional oral health care services is alarmingly low in Ouagadougou and self-medication appeared to be an important alternative source of care for the participants in the present study. Despite differences in study design, this pattern accords with previous surveys carried out in Nigeria [8], Ivory Coast [7] and South Africa [6]. It is interesting to note that urban studies conducted in Burkina Faso [22] and in Congo [23] revealed that adults reporting general illness symptoms also had low attendance at professional health services while self care was common practice.

Our study also emphasises the association between religious affiliation and the use of health facilities. This somewhat surprising finding may reflect the historical basis of the implementation of health services in Ouagadougou since the colonial period. Christian missionaries (Protes- tant or Catholic communities) have played a major role in providing of health care [24]. In Ouagadougou, the current oral health care services are mainly provided by nongovernmental not-for-profit health centres run by missionaries [14]. Similarly, a relationship between religion and the utilization of maternal and child health services was found in a recent study in Ghana, a country that borders Burkina Faso [25]. The authors speculated that religion represents a social structural attribute that may influence patterns of maternal health utilization.

The socio-economic level of the household is a key determinant of health seeking behaviour [3,26-28]. In our study, the socio-economic standard of the household was measured by a proxy index of material living conditions, which was strongly associated with the use of health care services. In addition, the bivariate analysis showed an association between the choice of oral health care and the regular settlements. The population groups living in irregular settlements were less likely to visit health professionals and also more likely not to seek treatment at all. The multivariate analysis did not confirm this pattern because 
Table 4: Logistic regression results on the factors associated with using health facilities among adults having experienced an oral problem $(n=809)$

\begin{tabular}{|c|c|c|c|}
\hline Independent variables & Odds ratio & $95 \% \mathrm{Cl}$ & $P$-value \\
\hline \multicolumn{4}{|l|}{ Predisposing socio-demographic factors } \\
\hline \multicolumn{4}{|l|}{ Age group, years } \\
\hline $15-24$ & 1.07 & $0.44-2.63$ & 0.877 \\
\hline $25-34$ & 2.65 & $1.48-4.74$ & 0.001 \\
\hline $35-44$ & 1.68 & $0.98-2.89$ & 0.059 \\
\hline $45-54$ & 1.46 & $0.78-2.73$ & 0.242 \\
\hline Over 54 & - & & \\
\hline \multicolumn{4}{|l|}{ Religion } \\
\hline Christian/Animist & 1.81 & $1.27-2.56$ & 0.001 \\
\hline Muslim & - & & \\
\hline \multicolumn{4}{|l|}{ Material living conditions of household } \\
\hline High & 3.39 & $2.11-5.43$ & $<0.001$ \\
\hline Moderate & 2.01 & $1.29-3.12$ & 0.002 \\
\hline Low & - & & \\
\hline \multicolumn{4}{|l|}{ Predisposing health belief factors } \\
\hline \multicolumn{4}{|c|}{ Oral diseases are as important as other health problems } \\
\hline Agree & 2.09 & $1.21-3.62$ & 0.009 \\
\hline Disagree/Don't know & - & & \\
\hline \multicolumn{4}{|c|}{ Going to the dentist is synonymous with pain } \\
\hline Disagree/Don't know & 0.47 & $0.33-0.66$ & $<0.001$ \\
\hline Agree & - & & \\
\hline \multicolumn{4}{|l|}{ Enabling factors } \\
\hline \multicolumn{4}{|l|}{ Social network } \\
\hline Active participation & 1.84 & $1.12-3.03$ & 0.016 \\
\hline Weak participation & - & & \\
\hline \multicolumn{4}{|l|}{ Means of transport in town } \\
\hline Moped or vehicle (car, taxi or bus) & 2.15 & $1.44-3.21$ & $<0.001$ \\
\hline On foot or bicycle & - & & \\
\hline \multicolumn{4}{|l|}{ Perceived need factors } \\
\hline \multicolumn{4}{|c|}{ Oral problem caused limitation or stopped any of usual activities } \\
\hline Yes & 3.43 & $2.38-4.93$ & $<0.001$ \\
\hline No/Don't know & - & & \\
\hline
\end{tabular}

of the inter-correlation between residential area and the index of material living conditions.

The perceived importance of oral health problems emerged as a significant factor in health service utilization in our study. It was not surprising that adults who paid less attention to oral diseases compared to general diseases were unlikely to seek health services. The perceived severity of symptoms was shown to be an essential determinant of treatment choice. This result is consistent with research showing that cultural beliefs and values may act to reinforce or inhibit the use of health services, depend- ing upon the reference group values $[4,29]$. Fear and anxiety are often suggested as barriers to use of dental services [30]. This was not the case in the present study, as those who were afraid of dentists were more likely to use dental services. This reflects the fact that dental visits are very unpleasant because the service often rendered for pain relief is extraction of teeth. This observation accords with findings about oral health service utilization among adults in China [31,32].

Access to health care facilities seems to be less of a problem in urban than in rural areas, although travel expenditure tends to increase rapidly in a large city like Ouagadougou. Furthermore, it is worth noting that oral health services are limited and mainly established in the central part of the city [14]. This may help to explain why having a moped or other vehicle appeared to be an enabling factor in using oral health care facilities. Thus, although distance in the big cities of developing countries may not represent a major problem for access to general health facilities [22], it is still a potential barrier to the use of oral health services.

The present study also indicates that active participation in social networks is an important determinant of oral health seeking behaviour in the event of oral affliction. The social networks mechanisms consist of advising about or facilitating access to particular health providers. Furthermore, the number of years spent in the city or having been born in Ouagadougou were not associated with use of oral health services. This may suggest that use of oral health services depends more on participation in urban networks than on the duration of urban life experience. Such findings corroborate various oral health care utilization studies carried out in industrialized countries $[3,33]$. Other studies conducted both in both developed and developing countries and focusing on general health seeking behaviour have also emphasized the influence of social networks as predictors of health care utilization [34,35].

\section{Conclusion}

Our data on the urban adult population in Burkina Faso showed that oral self-care accords with both traditional and modern self-medication practices. Out-of-pocket expenses for health services in general and for oral health services in particular may lead to widespread self-medication among the populations of developing countries. In addition, socio-cultural factors have been identified as significant in relation to use of oral health services. These factors can help identify groups "at risk" and assist in planning public health intervention programs.

For most urban centres in sub-Saharan Africa, the capacity of the oral health system is still insufficient to match the 
needs of all individuals suffering from pain or discomfort and to serve the population at large, especially in deprived communities. National health authorities should explore critical issues concerning self-medication for the prevention and treatment of oral symptoms before promoting the potential benefits of affordable alternative sources of care. Furthermore, decision-makers must seek to ensure that access to essential oral health care is improved. Such initiatives should pay specific attention to the poorest population groups and thereby also facilitate their access to health services.

\section{Competing interests}

The author(s) declare that they have no competing interests.

\section{Authors' contributions}

BV participated in protocol development and study design, conducted the field work, analysed and interpreted data, drafted and revised the manuscript. PEP took part in protocol development study design, supervision of data analysis, and writing and editing of the manuscript. FF participated in the study design, coordinated the field work and revised the manuscript. PM participated in the statistical analysis and revised the manuscript critically at different stages. JG managed and supervised the data collection and the statistical analysis. SO participated in protocol design and revised the manuscript. MH participated in the study design, in the data collection in the field and revised the manuscript. GS conceived the research program and participated in the writing of the manuscript. All authors contributed to the final version of the manuscript.

\section{Acknowledgements}

The authors are grateful to the population in Ouagadougou for their warm acceptance and to the team of interviewers for its great support in the field. We would like to thank also JF Cornu for his advice in statistical methods. Lastly, we thank both reviewers for their helpful suggestions for revising the draft. The programme was initiated in partnership with the Institut de Recherche pour le Développement (IRD), the Ministry of Health and the Institut de Recherche des Sciences de la Santé, Burkina Faso. This study was funded by IRD, Paris, France, and supported by the WHO Collaborating Centre for Community Oral Health Programmes and Research, University of Copenhagen, Copenhagen, Denmark.

\section{References}

I. WHO: World Health Report 2002: Reducing Risks, Promoting Healthy Life. Geneva, ; 2002:230.

2. Petersen PE: The World Oral Health Report 2003: continuous improvement of oral health in the 2 Ist century--the approach of the WHO Global Oral Health Programme. Community Dent Oral Epidemiol 2003, 3 I Suppl I:3-23.

3. Petersen PE Holst, D: Utilization of dental services. In Disease Prevention and oral Health Promotion: Socio-dental Sciences in Action Edited by: Cohen LK and Gift HC. Copenhagen: Munskgaard, ; 1995:34I-386.

4. Chen M, Andersen RM, Barmes DE, Leclercq MH, Lyttle CS: Comparing Oral Health Care Systems, A second international collaborative study. Edited by: Organization WH. Geneva,; 1997:350.
5. Varenne B, Petersen PE, Ouattara S: Oral health behaviour of children and adults in urban and rural areas of Burkina Faso, Africa. Int Dent J 2006, 56:61-70.

6. Westaway MS, Viljoen E, Rudolph MJ: Utilisation of oral health services, oral health needs and oral health status in a periurban informal settlement. $S A D J 1999,54: \mid 49-152$.

7. Samba M, Guinan JC, Sangare A, Da-Danho V, Bakayoko-Ly R: Itinéraire thérapeutique en odonto-stomatologie à Abidjan. Odontostomatol Trop 2004, 27:37-40.

8. Adegbembo AO: Household utilization of dental services in Ibadan, Nigeria. Community Dent Oral Epidemiol 1994, 22:338-339.

9. Mosha HJ, Scheutz F: Perceived need and use of oral health services among adolescents and adults in Tanzania. Community Dent Oral Epidemiol 1993, 21:129-132.

10. Ouendo EM, Makoutode M, Paraiso MN, Wilmet-Dramaix M, Dujardin B: Itinéraire thérapeutique des malades indigents au Bénin (pauvreté et soins de santé). Trop Med Int Health 2005, 10:179-186.

II. Tapsoba H, Deschamps JP: Use of medicinal plants for the treatment of oral diseases in Burkina Faso. J Ethnopharmacol 2006, 104:68-78.

12. Njoh AJ: Urbanization and development in sub-Saharan Africa. Cities 2003, 20:167-174.

13. Fournet F, Salem G: La santé dans les villes africaines, d'idées reçues à la définition d'une urgence de santé publique. Med Trop (Mars) 2004, 64:567-568.

14. Varenne B, Msellati P, Zoungrana C, Fournet F, Salem G: Reasons for attending dental-care services in Ouagadougou, Burkina Faso. Bull World Health Organ 2005, 83:650-655.

15. Vallee J FF Meyer PE, Harang M, Pirot F et Salem G: La télédétection, un appui à la stratification spatiale : stratification de la ville de Ouagadougou au Burkina Faso à partir d'une image panchromatique Spot 5. 2005.

16. Bennett S, Radalowicz A, Vella V, Tomkins A: A computer simulation of household sampling schemes for health surveys in developing countries. Int J Epidemiol 1994, 23:|282-I29|.

17. Andersen R, Newman JF: Societal and individual determinants of medical care utilization in the United States. Milbank Mem Fund Q Health Soc 1973, 5 1:95-124.

18. Andersen RM: Revisiting the behavioral model and access to medical care: does it matter? J Health Soc Behav 1995, 36: I- 10.

19. Milligan P, Nije A, Bennett S: Comparison of two cluster sampling methods for health surveys in developing countries. Int J Epidemiol 2004, 33:469-476.

20. Bostoen K, Chalabi Z: Optimization of household survey sampling without sample frames. Int J Epidemiol 2006, 35:75I-755.

21. Kiyak HA, Reichmuth M: Barriers to and enablers of older adults' use of dental services. J Dent Educ 2005, 69:975-986.

22. Develay A, Sauerborn R, Diesfeld HJ: Utilization of health care in an African urban area: results from a household survey in Ouagadougou, Burkina-Faso. Soc Sci Med 1996, 43: I6I I-1619.

23. Manzambi JK, Tellier V, Bertrand F, Albert A, Reginster JY, Van Balen $\mathrm{EH}$ : Les déterminants du comportement de recours au centre de santé en milieu urbain africain: résultats d'une enquête de ménage menée à Kinshasa, Congo. Trop Med Int Health 2000, 5:563-570.

24. Monné R: Secteurs sanitaires confessionnel et public. Quelle articulation? In Dieu dans la cité : dynamiques religieuses en milieu urbain ouagalais Edited by: CEAN . Bordeaux-Talence, ; 1999:57-90.

25. Gyimah SO, Takyi BK, Addai I: Challenges to the reproductivehealth needs of African women: On religion and maternal health utilization in Ghana. Soc Sci Med 2006.

26. Fassin $D$, Brousselle $C$ : Les enquêtes d'accès aux soins en Afrique. Problèmes méthodologiques. Rev Epidemiol Sante Publique 1991, 39:89-99.

27. Grytten J, Holst D: Do young adults demand more dental services as their income increases? Community Dent Oral Epidemiol 2002, 30:463-469.

28. Shaikh BT, Hatcher J: Health seeking behaviour and health service utilization in Pakistan: challenging the policy makers. J Public Health (Oxf) 2005, 27:49-54.

29. Davidson PL, Andersen RM: Determinants of dental care utilization for diverse ethnic and age groups. Adv Dent Res 1997, I I:254-262. 
30. Locker D, Liddell A, Burman D: Dental fear and anxiety in an older adult population. Community Dent Oral Epidemiol I99I, 19:120-124.

31. Petersen PE, Peng B, Tai BJ: Oral health status and oral health behaviour of middle-aged and ederly people in PR China. International Dental Journal 1997, 47:305-312.

32. Lo EC, Lin HC, Wang ZJ, Wong MC, Schwarz E: Utilization of dental services in Southern China. J Dent Res 200I, 80: I47I-I474.

33. Petersen PE, Nortov B: General and dental health in relation to life-style and social network activity among 67-year-old Danes. Scand J Prim Health Care 1989, 7:225-230.

34. Kroeger A: Anthropological and socio-medical health care research in developing countries. Soc Sci Med 1983, 17:147-161.

35. Fassin $D$, Jeannee $E$, Cebe $D$, Reveillon $M$ : Who consults and where? Sociocultural differentiation in access to health care in urban Africa. Int J Epidemiol 1988, 17:858-864.

\section{Pre-publication history}

The pre-publication history for this paper can be accessed here:

http://www.biomedcentral.com/1472-6963/6/164/pre pub

Publish with Bio Med Central and every scientist can read your work free of charge

"BioMed Central will be the most significant development for disseminating the results of biomedical research in our lifetime. "

Sir Paul Nurse, Cancer Research UK

Your research papers will be:

- available free of charge to the entire biomedical community

- peer reviewed and published immediately upon acceptance

- cited in PubMed and archived on PubMed Central

- yours - you keep the copyright 